\title{
Impact of COVID-19 Pandemic on Gynecological Oncology Care: Glimpse into Association of Gynecological Oncologists of India (AGOI) Perspective
}

\author{
Geetu Bhandoria $^{1}$ D - T. S. Shylasree ${ }^{2}$ Prashant Bhandarkar ${ }^{3} \cdot$ Vijay Ahuja $^{4} \cdot$ Amita Maheshwari $^{2}$. \\ Rupinder Sekhon ${ }^{5}$. S. P. Somashekhar ${ }^{4}$
}

Received: 18 April 2020/Revised: 26 May 2020 / Accepted: 30 May 2020/Published online: 15 June 2020

(C) Association of Gynecologic Oncologists of India 2020

\begin{abstract}
Purpose The notorious COVID 19 pandemic has caused rapid and drastic changes in cancer care worldwide in 2020. This online survey aims to assess the extent to which the pandemic has affected cancer care in gynecological oncology amongst members of the Association of Gynecological Oncologists of India (AGOI), a registered professional society founded in 1991.

Methods We developed and administered a cross-sectional, flash survey to members of AGOI in the first week of April 2020. Data were analyzed using Microsoft Office Excel 2016. Results were expressed as percentages of total responses excluding blank or unattended response. Overall theme-specific responses were described as a spectrum of findings, and related inferences were drawn.

Results Among approached practitioners, 90 responded to the survey, more than $80 \%$ were practicing consultants, and more than $50 \%$ from academic institutions. The results of the study showed that the ongoing pandemic had severely affected gynecological oncology practice and care amongst all respondents. There were modifications in diagnostic pathways, interventions, and follow-ups across all organ sites. There was a near-unanimous opinion on the use of general safety measures to combat the virus and to use complete PPEs in a high-risk situation. There were mixed responses to alternative educational activities, especially using electronic technology and distant learning methods. There was optimism among respondents with regards to the current situation normalizing in 3-6 months.

Conclusion This study documents the pandemic affected scenario of gynecological cancer care and perceptions of Gynecological Oncologists in India. A significant effect on all aspects of cancer care was observed. Technological learning methods, both for patient care and educational activities, were being adopted by many respondents.
\end{abstract}

Keywords COVID-19 · Pandemic · Gynecological oncology care · Survey · AGOI

\section{Introduction}

Electronic supplementary material The online version of this article (https://doi.org/10.1007/s40944-020-00421-8) con-

tains supplementary material, which is available to authorized users.

Geetu Bhandoria

doctor_071277@yahoo.co.in

1 Department of Obstetrics and Gynecology, Command Hospital, Pune, Maharashtra, India

2 Tata Memorial Hospital, Mumbai, Maharashtra, India

3 Bhabha Atomic Research Centre Hospital, Mumbai, Maharashtra, India
On 31 December 2019, the World Health Organization (WHO) China Country Office was informed of cases of pneumonia of unknown etiology (unknown cause) detected

4 Manipal Comprehensive Cancer Centre, Bangalore, Karnataka, India

5 Rajiv Gandhi Cancer Institute \& Research Centre, New Delhi, India 
in Wuhan City, Hubei Province of China. The causal agent was identified as a novel coronavirus (2019-nCOV) on 7 January 2020 [1]. 2019-nCOV was renamed as the SARSCov-2 virus and disease caused as COVID-19, most likely a zoonotic disease [2, 3]. On 30 January 2020, following the recommendations of the Emergency Committee, the WHO Director-General declared that the outbreak constitutes a Public Health Emergency of International Concern (PHEIC) or pandemic [4]. There has been an unexpected and exponential rise in the number of cases all over the globe, with over 1.8 million cases worldwide and more than 0.11 million fatalities [5]. The impact of COVID-19 is substantial and has already caused significant economic, social, and health-care disruptions worldwide [6-8]. India's first COVID-19 case was found on 30 January 2020. The surge reached 14,352 confirmed COVID cases with 486 deaths at the time of submission of this study, i.e., 17 April 2020 , generating a case-fatality rate of $3 \%$ [9].

\section{Methodology}

We conducted a cross-sectional self-administered online survey for this study purpose in the first week of April 2020. The survey was piloted and further refined based on feedback among expert gynecologic oncology colleagues. The self-administered survey posed groups of questions on various challenges about management changes regarding gynecologic cancers, concerns about personal protection measures, and social perspectives. Questions with ambiguous intent or options were refined. The survey was disbursed through www.surveymonkey.com to personal mail addresses of members of The Association of Gynecological Oncologists of India (AGOI) and WhatsApp groups. There was a set of closed and open-ended questions whose answers could be marked on a numerical scale. At the end of the survey period, responses received were downloaded as a form of comma-separated values (CSV) file. Data were analyzed using Microsoft Office Excel 2016. Results were expressed as percentages of total responses excluding blank or unattended response. Overall theme-specific responses were expressed as a spectrum of finding and related inferences were drawn.

\section{Results}

We sent the survey to 567 AGOI members (electronic mail recipients and members of the AGOI WhatsApp group), 520 finally received survey links (47 emails bounced or participants opted out of survey). We received 90 responses, yielding a net response rate of $12 \%$. Among respondents, Gynecological oncologists were 68\%, Gynecologists
$12 \%$, Surgical Oncologists $11 \%$, and finally Medical Oncologists and Radiation Oncologists $4 \%$ each. Half of the respondents were from the academic hospital, followed by the cancer center $(31 \%)$, private hospitals $(15.56 \%)$, and $3 \%$ from local or regional hospitals. $49 \%$ of respondents were consultants with experience of 10 years or more, while $23 \%$ were consultants with below ten years of experience, and $19 \%$ were residents and $9 \%$ fellows.

The majority of respondents $(75 \%)$ told to have been following institutional or national guidelines; rest $(25 \%)$ were following some international guidelines. $60 \%$ of respondents expressed a lack of scientific evidence among guidelines.

Tele-consultation services were reported to have been started by $58 \%$ of respondents, while $16 \%$ told to have facility under process. 'New cancer cases' were being seen by $44 \%$ of respondents in accordance with institutional guidelines, $35 \%$ were deferring to see these patients, and $21 \%$ had not got any new case at the time of this survey. Cervical Intraepithelial Neoplasia-3 (CIN-3) was being managed conventionally by $30 \%$, while $65 \%$ of respondents were postponing definitive management by three months.

\section{Early-Stage Cervical Cancer}

Standard surgical management was reported by $34 \%$ of respondents, $33 \%$ were offering chemoradiotherapy for all cases, and the remaining were following neoadjuvant chemotherapy or radical radiotherapy (RT). (Table 1).

\section{Early-Stage Endometrial Cancer}

Almost half of the respondents (48\%) were continuing standard surgery, others were offering neoadjuvant hormonal therapy $(22 \%)$ or neoadjuvant chemotherapy followed by delayed surgery (16\%), and Levonorgestrel Intrauterine system (LNG-IUS) followed by surgery $(15 \%)$ (Table 1).

\section{Early-Stage Vulvar Cancer}

$40 \%$ were following close observation, $28 \%$ were continuing to offer standard surgery, and the rest $(32 \%)$ were offering neoadjuvant options with chemo or RT. (Table 1).

Most respondents (83-92\%) continued to treat advanced-stage gynecological cancers, though most of them have 'modified' standard management as per institutional protocols. (Fig. 1). Most respondents (80\%) felt strongly about 'cessation of elective benign surgeries' and $70 \%$ for 'cessation of cancer surgeries.' Most respondents $(68 \%)$ were not in favor of postponing diagnostic services for 'new' patients. Most (82\%) supported the suspension or 
Table 1 Distribution of various treatment modalities for 'Early-stage' disease (percentages of responses received)

\begin{tabular}{|c|c|c|c|c|}
\hline \multirow{2}{*}{$\begin{array}{l}\text { Malignancy } \\
\text { Cervix }\end{array}$} & \multicolumn{4}{|c|}{ Management options (\% responses) } \\
\hline & $\begin{array}{l}\text { Conventional surgery still } \\
\text { being done at my center } \\
(34)\end{array}$ & CCRT for all (33) & $\begin{array}{l}\text { NACT followed by } \\
\text { delayed surgery } \\
(28)\end{array}$ & $\begin{array}{l}\text { NART followed by delayed } \\
\text { surgery }(6)\end{array}$ \\
\hline Endometrium & $\begin{array}{l}\text { Conventional surgery still } \\
\text { being done at my center } \\
(48)\end{array}$ & $\begin{array}{l}\text { LNG IUS followed by delayed } \\
\text { surgery (15) }\end{array}$ & $\begin{array}{l}\text { NACT followed by } \\
\text { delayed surgery } \\
\text { (16) }\end{array}$ & $\begin{array}{l}\text { Neo-adjuvant hormone therapy } \\
\text { followed by delayed surgery } \\
\text { (22) }\end{array}$ \\
\hline Vulva & $\begin{array}{l}\text { Conventional surgery still } \\
\text { being done at my center } \\
\text { (28) }\end{array}$ & $\begin{array}{l}\text { Close observation followed by } \\
\text { surgery at earliest opportunity } \\
(40)\end{array}$ & $\begin{array}{l}\text { NACT followed by } \\
\text { delayed surgery } \\
\text { (14) }\end{array}$ & $\begin{array}{l}\text { NART followed by delayed } \\
\text { surgery (18) }\end{array}$ \\
\hline
\end{tabular}

\section{Management options in advanced stage disease}

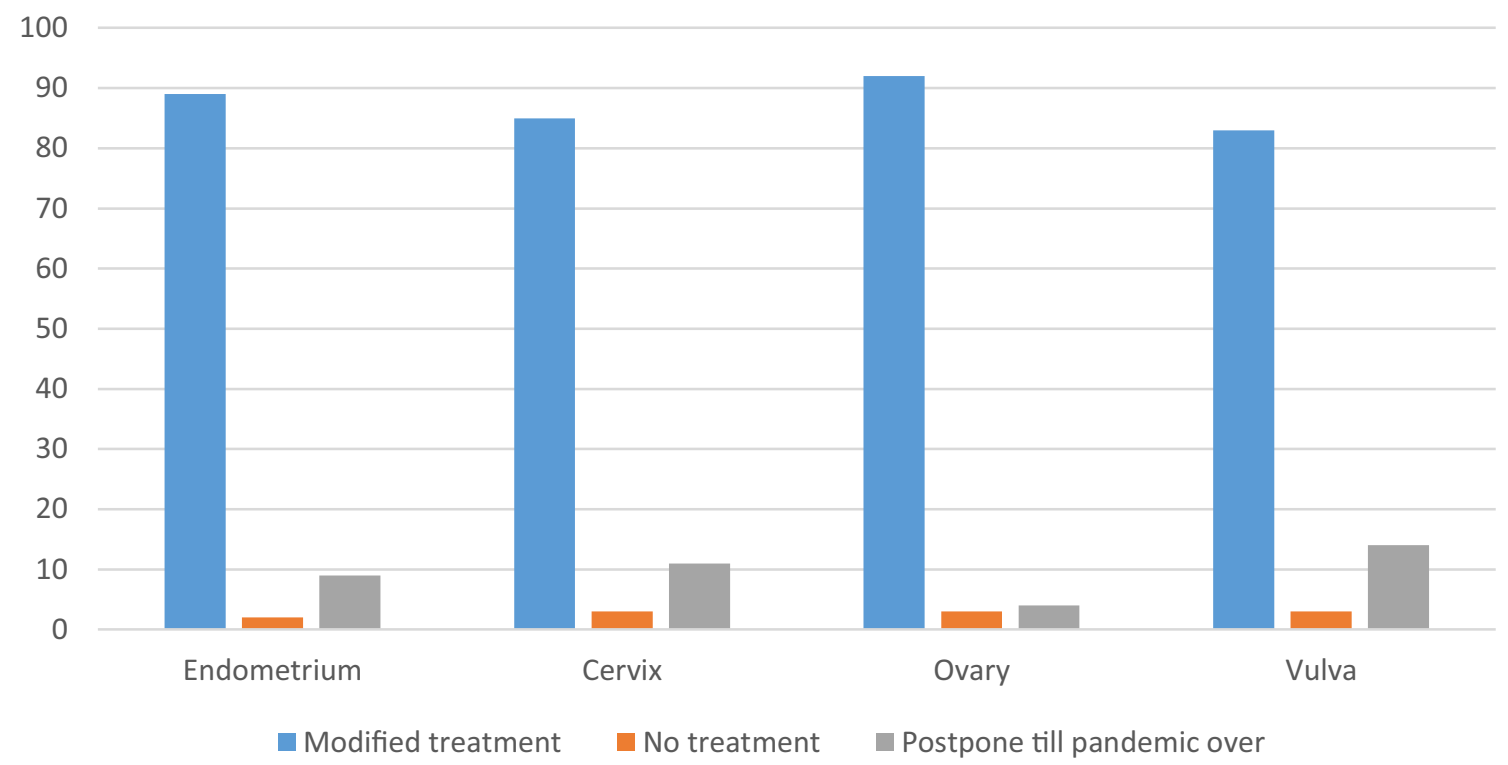

Fig. 1 Management options for 'Advanced' stage disease

modification of standard 'follow-up protocols' of gynecological cancer patients.

$71 \%$ of respondents felt that elective benign surgeries should be postponed 'as long as necessary,' to divert resources for COVID care. However, only $37 \%$ felt a delay of two weeks is acceptable for cancer surgeries, and another $36 \%$ felt these surgeries could be delayed for six weeks. New patients' diagnostic services could be delayed up to two weeks, was reported by $52 \%$ of respondents, and $27 \%$ felt a delay of six weeks was acceptable.

Most respondents have modified 'follow-up' protocols, mostly with a 'less frequent' follow-up approach. Patients with more than five years of disease-free survival were not being seen presently by $54 \%$ of respondents. (Fig. 2).

Personal protection equipment (PPE) usage as a preventive measure against contracting COVID-19 was suggested by $75 \%$ of respondents when dealing with suspected/confirmed COVID patients. Another 22\% reported that all $\mathrm{HCW}$ should use $\mathrm{PPE}$ at all times during health care delivery. Most respondents (92\%) believed that a combination of social distancing, face mask (any type), and hand hygiene was an effective means to contain the pandemic.

Only $3 \%$ of respondents reported having operated on a confirmed COVID case at the time of answering this survey, while another $4 \%$ were awaiting COVID test results on their patients. Current Hydoxy-chloroquine (HCQ) prophylaxis use was reported by $22 \%$ of respondents, $50 \%$ wished to take it but were waiting for more robust evidence to support its use, $12 \%$ wanted to take it but were concerned about cardiac toxicity, and $16 \%$ did not want to take it at all.

Various alternative learning methods were suggested by respondents as depicted in Fig. 3. 54\% of respondents felt 


\section{Follow up protocol}

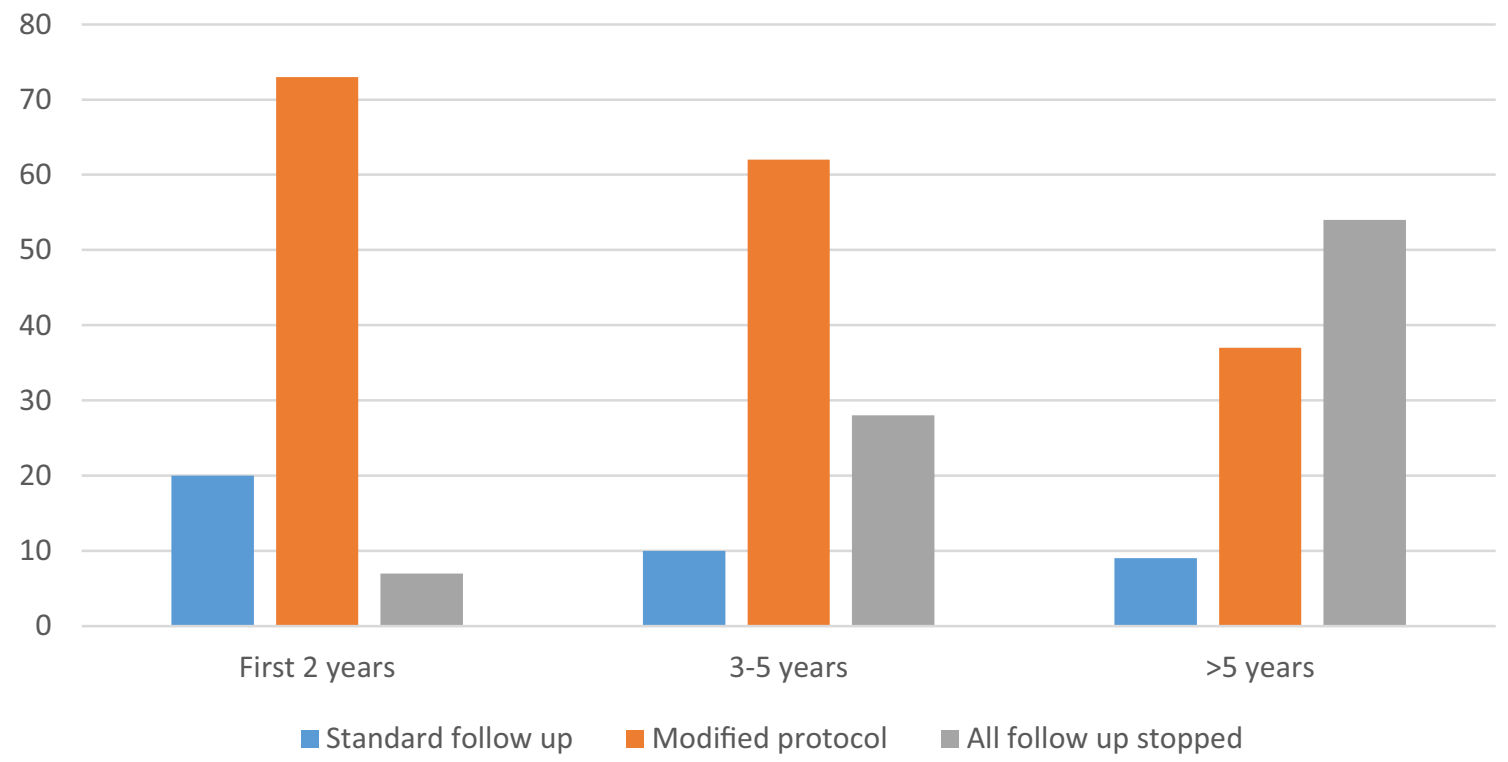

Fig. 2 Suggested follow-up protocol, post-treatment completion, weighing positive as well as negative consequences

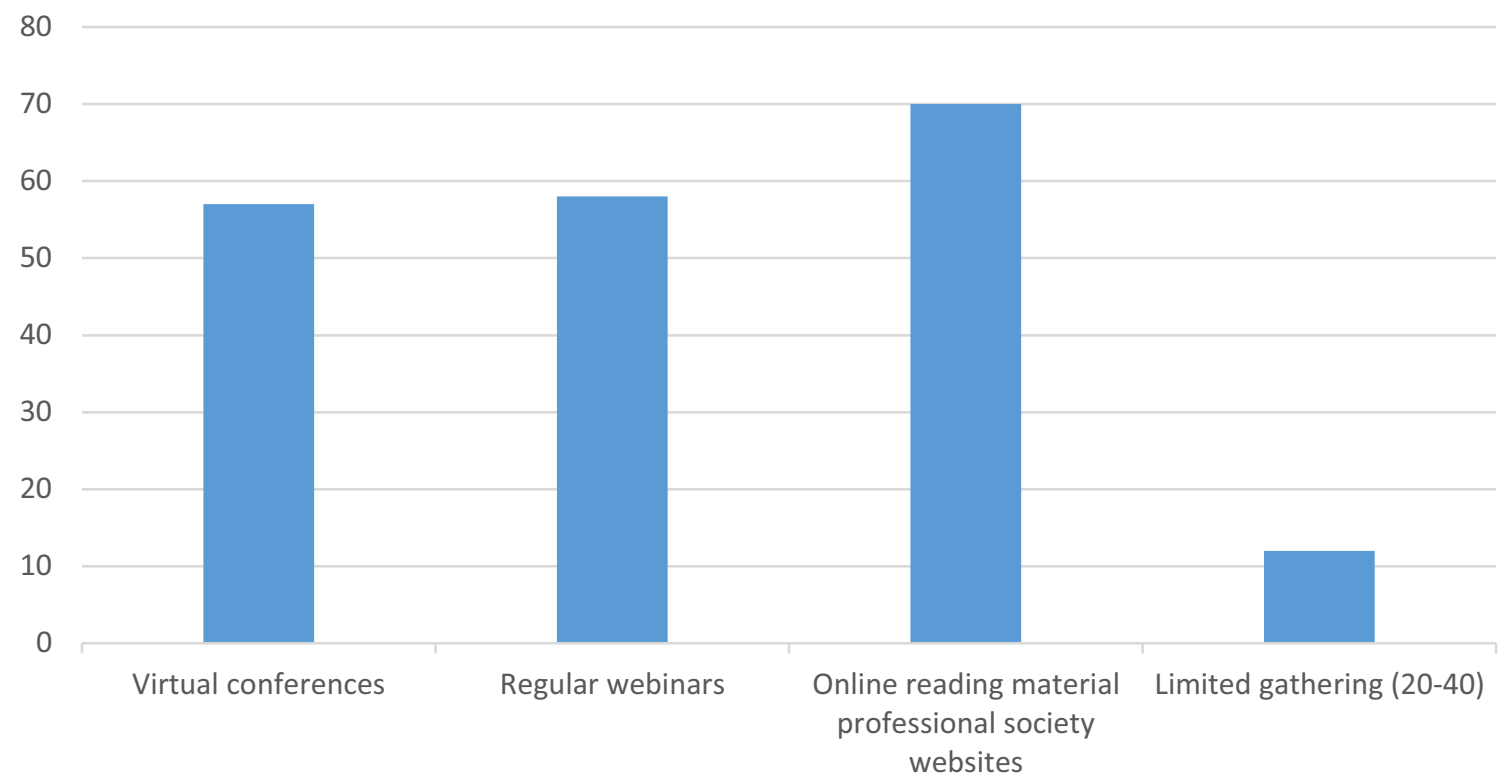

- Series 1

Fig. 3 Alterative learning methods if lock-down/travel restrictions extend beyond 6 months

that these alternative learning methods were not good enough, as there would be 'less opportunity for professional interaction,' $42 \%$ were concerned about different geographic time zones during online events, $48 \%$ were worried about acquiring new digital/social media skills to be part of e-learning, and lastly, 26\% felt that there would be less opportunity for networking in e-learning events.

\section{Discussion}

AGOI mostly consists of practicing Gyn-oncologists, gynecologists with a particular interest in Gyn- oncology or preventive oncology, surgical oncologists, medical and radiation oncologists. It was encouraging that two-thirds of the respondents (67\%) were practicing Gyn-oncologists. More than $80 \%$ of respondents were from academic 
institutions or cancer centers. One in two respondents had an experience of more than ten years, which gave a realistic view of the impact of the pandemic on clinical practice in gynecological oncology. At the time of the survey, many centers and institutions in India were in the process of formulating their guidelines/webinars or published guidelines that resembled the logistics of their working environment [9]. Hence two-third of respondents were following some COVID cancer guidelines to manage gynecological cancers [10-19]. Bench to bedside research on COVID-19 was being generated fast track in the world, making clinicians uncomfortable as they were not used to this speed. This might be why $60 \%$ of respondents expressed a lack of scientific evidence among existing guidelines.

Cervical cancer was reportedly managed with standard optimal therapy (surgery/chemo-radiation), in two-thirds of the patients [20, 21]. One third were given neoadjuvant chemotherapy to delay surgery, which is not the standard of care presently, but is a valid alternative if resources are stretched [22]. With regards to early endometrial cancer, surgery is the mainstay of treatment and preferably Minimally Invasive Surgery (MIS) [23], but only one in two underwent surgery. Some form of therapy was advocated (hormonal/NACT) so that surgery could be delayed [24]. There are concerns with the safety of MIS regarding smoke evacuation and intra-abdominal pressure, which might have altered the clinician's decision to delay MIS [25]. Many early vulvar cancers were managed by observation, and only a few received surgery or neoadjuvant therapy. Vulvar cancers constitute less than $10 \%$ of the surgical workload, so interpretation is difficult as numbers treated during this time might be few. On speculation, the elderly age group delayed healing of the surgical wound, and prolonged hospitalization might have shifted the balance towards observation with intent to delay surgery compared to the cervix or endometrium [26].

Amongst all interventions in early-stage gynecological cancers, surgery, when indicated, appears to be the best possible solution where recovery from surgery is good, and the probability of acquiring the virus is less in a screened patient. There is an increased risk of acquiring viral infection as RT requires multiple hospital visits, chemotherapy suppresses immunity, and increases susceptibility to infection $[13,14]$. There might have been obvious logistic reasons for following one treatment over the other such as lack of availability of slots to treat, inability to travel to a center with RT or surgical facility, or reduced number of medical/nursing staff working due to quarantine and lockdown issues. The overall oncological outcomes of early gynecological cancers are excellent; hence they need to be evaluated and compared to preCOVID literature as there are deviations from standard management now globally. It would remain to be seen how many patients developed COVID-19 due to cancer-related treatment and contributed to overall morbidity and mortality.

There is not much controversy in starting treatment for advanced gynecological cancers in the survey results. Most of these comprise of advanced ovarian cancers, and neoadjuvant treatment is non-inferior to extensive cytoreductive surgery [27]. There is a clause on performing extensive cytoreductive surgery (CRS) during the pandemic as intensive care beds need to be reserved, preferably for COVID patients. Reduced blood donation camps leading to a shortage of blood products also is a limiting factor for performing CRS with or without HIPEC.[13, 14]. Increased susceptibility to the virus is the main concern in advanced ovarian cancer patients as they are generally over 60 years, frail, and immune-suppressed during chemotherapy [28-30].

More than $70 \%$ of respondents felt that a delay of two to six weeks in the active treatment of gynecological cancers is acceptable. This is in keeping with cancer guidance of referral to treatment of 30-day cutoff in most developed countries for starting active intervention from diagnosis and also the time frame for advocating adjuvant therapy [14-16].

As expected, the response rate to either postponement or modifications in the 'follow-up' of treated patients was high. Despite many years of discussion, there is always resistance to change traditional physical follow up methods all over the world [31]. Now, the pandemic has changed the way we work by incorporating telemedicine [32]. Whether this will permanently change the way we consult patients in the future remains to be seen [30]. This appears to be a reasonable learning period for tele-follow-ups for cancer survivors for many cancer centers in India [9].

Most practitioners in the survey felt that general measures effectively contained the pandemic in day to day practice and complete PPEs to be reserved for workers dealing with high-risk patients. A common sense, rationed approach to the availability of resources like PPEs and the magnitude of this pandemic is being followed cautiously not only in India but all over the world [33, 34]. There was a mixed response to HCQ prophylaxis as the evidence and availability are an issue $[35,36]$. It has been recommended both by CDC and ICMR, after showing promise in several studies in vivo [37, 38]. But there have been certain concerns raised about potential cardiac side effects, especially in combination with azithromycin or individual with underlying cardiac conditions. Responders have shown similar concerns. Studies on HCQ prophylaxis are still evolving, and there is no consensus worldwide on HCQ prophylaxis for health care workers. 
As per GLOBOCAN estimates, India had 96,922 new cervical cancers, 36,170 new ovarian cancers, and 13,328 new endometrial cancers in 2018 [39]. The ongoing pandemic has forced a delay in cancer management due to several reasons cited above. This is likely to have an adverse effect on overall cancer care. We may soon be facing a bi-modal peak of cancer deaths; the imminent spike of those with decimated immunity falling victim to Covid-19 and the latent toll on those whose treatments were de-intensified, delayed or canceled altogether. To survive SARS-CoV-2 only to then succumb to an undertreated cancer would be a Pyrrhic victory. The acuteness of infection and the chronicity of malignancy are the Scylla and Charybdis between which oncologists and their patients must now chart a very cautious course indeed [40].

\section{Conclusions}

These are unprecedented times for health-care, even more so for the oncology community. We have to adapt to the requirements of patients, caregivers, and institutions, in consonance with the stage of ongoing pandemic. Multidisciplinary tumor board discussions, keeping patients involved in decision-making, and adopting a safe approach for both patients and health care workers will be vital in overcoming the crisis.

Acknowledgements We would like to acknowledge Delia Cortes Guiral, Surgical Oncologist and Peritoneal surface malignancy surgeon from Spain and her team, whose survey was adopted and expanded for this study.

\section{Compliance with ethical standards}

Conflict of interest None of the authors have any conflicts of interests for this study.

\section{References}

1. World Health Organization. Coronavirus disease 2019 (COVID19): Situation report-1

2. Andersen KG, Rambaut A, Lipkin WI, Holmes EC, Garry RF. The proximal origin of SARS-CoV-2. Nat Med. 2020;26(4):450-2. https://doi.org/10.1038/s41591-020-0820-9.

3. European Centre for Disease Prevention and Control

4. World Health Organization. Coronavirus disease 2019 (COVID19): Situation report-11

5. World Health Organization. Coronavirus disease 2019 (COVID19): Situation report- 85

6. Verity R, Okell LC, Dorigatti I, Winskill P, Whittaker C, Imai N, Cuomo-Dannenburg $\mathrm{G}$ et al. Estimates of the severity of coronavirus disease 2019: a model-based analysis. Lancet Infect Dis. Doi: 10.1016/S1473-3099(20)30243-7 (Accessed 3 April 2020).
7. M Reeves, P Carlsson-Szlezak, K Whitaker, M Abraham (2020) Post-COVID Era. BCG Henderson Institute, viewed 5 April 2020, https://www.bcg.com/en-in/publications/2020/8-ways-com panies-can-shape-reality-post-covid-19.aspx

8. Blair Nimmo. 2020. Business continuity in a COVID-19 world. KPMG, viewed 5 April 2020, https://home.kpmg/xx/en/home/ insights/2020/03/business-continuity-in-a-covid-19-world.html

9. https://www.kaggle.com/sudalairajkumar/covid19-in-india. Accessed 25 May 2020

10. The Tata Memorial Centre COVID-19 Working Group. The COVID-19 pandemic and the Tata Memorial Centre response. Indian J Cancer 0000;00:00-00. Doi: 10.4103/ijc.IJC_250_20

11. Burki TK Cancer Guidelines during the COVID-19 Pandemic. Lancet Oncol. Accessed 3 April 2020. Doi: 10.1016/S14702045(20)30217-5

12. You B, Ravaud A, Canivet A, Ganem G, Giraud P, Guimbaud R, Kaluzinski L, et al. The official french guidelines to protect patients with cancer against SARS-CoV-2 infection. Lancet Oncol. 2020. https://doi.org/10.1016/S1470-2045(20)302047(Accessed 3 April).

13. Burki TK Cancer care in the time of COVID-19. Lancet Oncol. Doi: 10.1016/S1470-2045(20)30201-1. Accessed 3 April 2020

14. BGCS framework for care of patients with gynaecological cancer during the COVID-19 pandemic. British Gyn Cancer Soc. Final. 22 March 2020

15. Pothuri B, Alvarez Secord A, Armstrong D, Chan J, Huh W, Kesterson J, Liu J, Moore K, Nickles Fader A, Westin S, Naumann W Anti-cancer therapy and clinical trial considerations for gynecologic oncology patients during the COVID-19 pandemic crisis: 3 April 2020. https://www.sgo.org/clinical-practice/covid19-communique/

16. Ramirez, Pedro T, Luis Chiva, Ane Gerda Z Eriksson, Michael Frumovitz, Anna Fagotti, Antonio Gonzalez Martin, Anuja Jhingran, and Rene Pareja. "COVID-19 Global Pandemic: Options for Management of Gynecologic Cancers. "International Journal of Gynecologic Cancer, 27 March, 2020, ijgc2020-001419. https://doi.org/10.1136/ijgc-2020-001419.

17. Masumi Ueda, Renato Martins, Paul C. Hendrie, Terry McDonnell, Jennie R. Crews, Tracy L. Wong, Brittany McCreery, et al. "Managing Cancer Care During the COVID-19 Pandemic: Agility and Collaboration Toward a Common Goal." Journal of the National Comprehensive Cancer Network J Natl Compr Canc Netw, 2020, 1-4.

18. Considerations on gynecologic cancer management during covid19 pandemic. Brazilian society of surgical oncology statement. BSSO. 3 April 2020

19. COVID-19: Elective Case Triage Guidelines for Surgical Care. American college of surgeons. 24 March 2020. https://www.facs. org/covid-19/clinical-guidance/elective-case. Accessed 26 May 2020.

20. ANZGOG \& COVID-19: 31 March 2020 Statement. https:// www.anzgog.org.au/anzgog-covid-19/. Accessed 26 May 2020.

21. Shrivastava S, Mahantshetty U, Engineer R, et al. Cisplatin chemoradiotherapy vs radiotherapy in FIGO stage IIIB squamous cell carcinoma of the uterine cervix: a randomized clinical trial. JAMA Oncol. 2018;4(4):506-13. https://doi.org/10.1001/jamaon col.2017.5179.

22. Datta NR, Stutz E, Liu M, et al. Concurrent chemoradiotherapy vs. radiotherapy alone in locally advanced cervix cancer: a systematic review and meta-analysis. Gynecol Oncol. 2017;145(2):374-85. https://doi.org/10.1016/j.ygyno.2017.01. 033.

23. Marchetti C, Fagotti A, Tombolini V, Scambia G, De Felice F. Survival and toxicity in neoadjuvant chemotherapy plus surgery versus definitive chemoradiotherapy for cervical cancer: a 
systematic review and meta-analysis. Cancer Treatment Rev Cancer Treatment Rev. 2019. https://doi.org/10.1016/j.ctrv.2019. 101945.

24. NCCN Clinical Practice Guidelines in Oncology (NCCN Guidelines): Uterine neoplasms. Version 1.2020-06 Mar 2020. https://www.nccn.org/professionals/physician_gls/pdf/uterine. pdf. Accessed 26 May 2020.

25. Dolmans M-M, Lambertini M, Macklon KT, Santos TA, RuizCasado A, Borini A, Bordes V, Frith L, Van Moer E, Germeyer A. european recommendations for female fertility preservation (EU-REFER): a joint collaboration between oncologists and fertility specialists. Crit Rev Oncol/Hematol. 2019;138:233-40. https://doi.org/10.1016/j.critrevonc.2019.03.010.

26. AGES and EAES recommendations regarding surgical response to covid-19 crisis. Aurora Pryor.29 Mar 2020

27. Mert I, Cliby WA, Bews KA, Habermann EB, Dowdy SC. Evidence-based wound classification for vulvar surgery: implications for risk adjustment. Gynecol Oncol. 2019;154(2):280-2. https:// doi.org/10.1016/j.ygyno.2019.06.008.

28. Coleridge SL, Bryant A, Lyons TJ, Goodall RJ, Kehoe S, Morrison J. Chemotherapy versus surgery for initial treatment in advanced ovarian epithelial cancer. Cochrane Database Systematic Rev 2019, Issue 10. Art. No.:CD005343. doi:10.1002/ 14651858.CD005343.pub4

29. Zhou F, Ting Y, Ronghui D, Guohui F, Ying L, Zhibo L, Xiang J, et al. Clinical course and risk factors for mortality of adult inpatients with COVID-19 in Wuhan, China: a retrospective cohort study. Lancet. 2020;395(10229):1054-62. https://doi.org/ 10.1016/S0140-6736(20)30566-3.

30. Guan W-j, Ni Z-y, Hu Y, Liang W-h, Ou C-q, He J-x, Liu L, et al. Clinical characteristics of coronavirus disease 2019 in China. N Engl J Med. 2020. https://doi.org/10.1056/NEJMoa2002032.

31. The Lancet Oncology. COVID-19: Global consequences for oncology. Lancet Oncol. 2020;21(4):467. https://doi.org/10.1016/ S1470-2045(20)30175-3.

32. Salani R, Khanna N, Frimer M, Bristow RE, Chen LM. An update on post-treatment surveillance and diagnosis of recurrence in women with gynecologic malignancies: society of gynecologic oncology (SGO) recommendations. Gynecol Oncol. 2017;146(1):3-10. https://doi.org/10.1016/j.ygyno.2017.03.022.

33. Hollander JE, Carr BG. Virtually perfect? telemedicine for Covid-19 [published online ahead of print, 202011 March]. N Engl J Med. 2020. https://doi.org/10.1056/NEJMp2003539.

34. Laura M, Leung T. Evaluating the effectiveness of social distancing interventions against COVID-19. MedRxiv. 2020. https:// doi.org/10.1101/2020.03.27.20044891.

35. Information for Clinicians on Therapeutic Options for Patients with COVID-19. 11 April 2020. https://www.cdc.gov/cor onavirus/2019-ncov/hcp/therapeutic-options.html. Accessed 26 May 2020.

36. Liu J, Cao R, Xu M, Wang X, Zhang H, Hu H, Li Y, Hu Z, Zhong W, Wang M. Hydroxychloroquine, a less toxic derivative of chloroquine, is effective in inhibiting SARS-CoV-2 infection in vitro. Cell Discovery. 2020;6(1):16.

37. Recommendation for empiric use of hydroxy-chloroquine for prophylaxis of SARS-CoV-2 infection. 11 April 2020. https:// icmr.nic.in/sites/default/files/upload_documents/HCQ_Recom mendation_22March_final_MM_V2.pdf. Accessed 26 May 2020.

38. Leung K, Wu JT, Liu D, Leung GM (2020) First-wave COVID19 transmissibility and severity in china outside hubei after control measures, and second-wave scenario planning: a modelling impact assessment. The Lancet. Doi: 10.1016/S01406736(20)30746-7 (Accessed 15 April, 2020).

39. https://gco.iarc.fr/today/data/factsheets/populations/356-indiafact-sheets.pdf. Accessed 26 May 2020.

40. Lewis MA. Between scylla and Charybdis-oncologic decision making in the time of covid-19. N Engl J Med. 2020. https://doi. org/10.1056/NEJMp2006588.

Publisher's Note Springer Nature remains neutral with regard to jurisdictional claims in published maps and institutional affiliations. 